\title{
Development of A Simple Removable Aliphatic Template for Remote meta-Selective C-H Functionalization: Experimental and Computa- tional Studies
}

\author{
Perla Ramesh, Chinnabattigalla Sreenivasulu, Koteswara Rao Gorantla, Bhabani S. Mallik*, Gedu
} Satyanarayana*

Department of Chemistry, Indian Institute of Technology Hyderabad, Kandi, Sangareddy 502285, Telangana, India

\begin{abstract}
The remote meta-selective $\mathrm{C}-\mathrm{H}$ bond functionalization of aromatic compounds is one of the most challenging yet valuable aims in synthetic organic chemistry. Despite notable recent achievements, only two types of aromatic templates including nitrile based aromatic templates and $\mathrm{N}$-aromatic templates used as directing group templates in the methodologies reported so far. No aliphatic "directing group (DG)" template was developed till the date. Herein, we have successfully unveiled a simple and inexpensive removable aliphatic template as an effective DG template in promoting remote meta-C- $\mathrm{H}$ olefination of arenes for the first time. Remarkably, the template was achieved in excellent yields in just two steps and without column chromatography purification. The protocol is an efficient, economical and practical approach in achieving meta-C-H olefination in good to excellent isolated yields and high levels of meta-selectivity under mild conditions. A wide variety of substituted arenes and olefin coupling partners are well tolerated in this reaction. Moreover, the aliphatic template is found to be advantageous due to its easy synthesis, easy installation/removal, and recycle. We believe that this strategy offers new opportunities for the future development of new DG templates to promote site-selective $\mathrm{C}-\mathrm{H}$ functionalizations.
\end{abstract}

\section{Introduction:}

The direct catalytic site-selective functionalization of unreactive $\mathrm{C}-\mathrm{H}$ bonds has emerged as an innovative highly atomefficient and step-economical sustainable approach for the rapid and streamlined synthesis of versatile potential chemical targets relevant to pharmaceuticals, natural products, materials and agrochemicals from relatively simple precursors. ${ }^{1}$ One of the major challenges is to achieve high positional-selectivity along with the installation of diverse functional groups because $\mathrm{C}-\mathrm{H}$ bonds are ubiquitous in organic frameworks with similar reactivity. A large number of promising methodologies have been developed from the last few decades to render functionalization of the unreactive $\mathrm{C}-\mathrm{H}$ bond at a selective position a viable proposition. Among a plethora of site-selective $\mathrm{C}-\mathrm{H}$ bond transformation reactions, the "directing group (DG)" strategy has been one of the most prevailing practical synthetic methodologies to achieve $\mathrm{C}-\mathrm{H}$ functionalization at both aromatic and aliphatic systems with high siteselectivity. $^{2-5}$ In this context, a major challenge is to design and development of an innovative "directing group (DG)" to control reactivity and regioselectivity of the intermolecular $\mathrm{C}-\mathrm{H}$ functionalization. Despite, a myriad of reactions has been explored in the DG-assisted ortho- $\mathrm{C}-\mathrm{H}$ functionalization from the last few decades; ${ }^{6}$ however, selective meta-C-H functionalization of aromatic compounds are still in their infancy and remains persistent challenging. ${ }^{7}$ Among literature reported templates for the selective meta-C-H functionalization, some of them are not removable or recyclable, which greatly compromise with the limited scope and synthetic application of reactions. $^{8}$

In 2012, Yu's pioneering research work discovered a cleavable, U-shaped linear "end-on" nitrile containing auxiliary as a template to access selective meta-C-H activation through the formation of a macrocyclic cyclophane-like pre-transition state. ${ }^{9}$ This breakthrough "Yu-turn" report has given rise to a few number of aromatic auxiliaries as directing templates from various research groups including Maiti, ${ }^{10,11} \mathrm{Tan}^{12}{ }^{12} \mathrm{Li},{ }^{13}$ and $\mathrm{Jin}^{14}$ along with his research group. ${ }^{15,16}$ The DG aromatic templates tethered arene substrates of various functional groups including carboxylic acids, alcohols, and amines were selectively functionalized at remote meta-position.

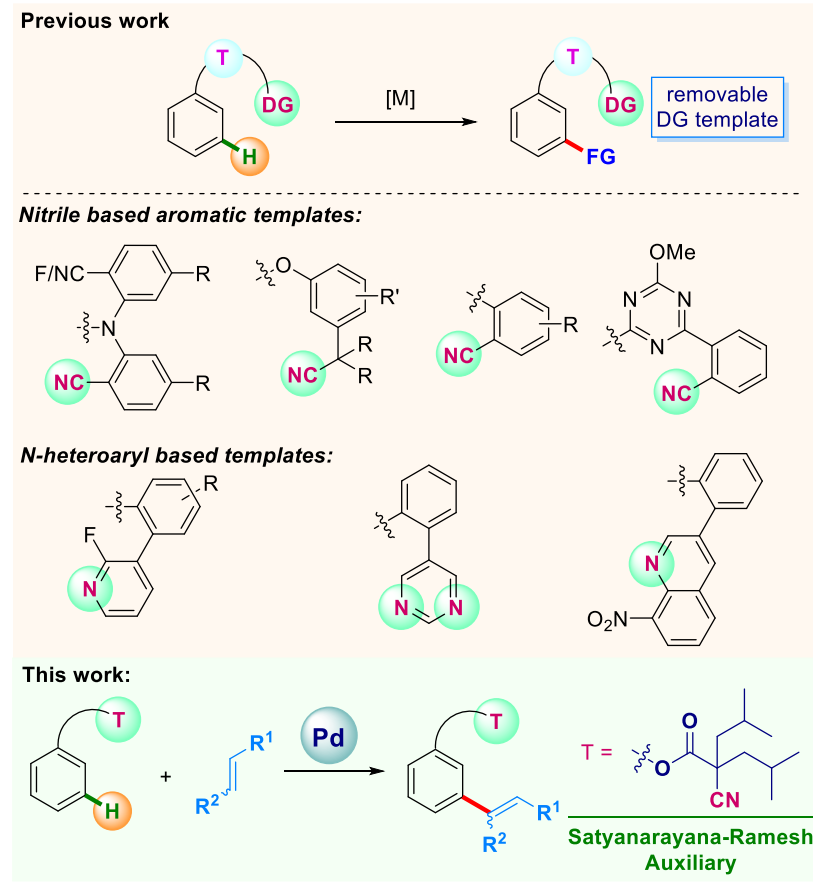

Figure 1. DG templates for remote meta-C-H functionalizations. 
DG templates to functionalize aryl meta- $\mathrm{C}-\mathrm{H}$ bonds are generally classified into two categories at present (Figure 1): ${ }^{7}$ (a) nitrile based aromatic templates as elegantly devised by $\mathrm{Yu}^{9,15}$ and others, ${ }^{10,12-14}$ (b) $N$-heteroaryl based templates typically realized by $\mathrm{Yu}^{16}$ and Maiti. ${ }^{11}$ The aromatic nitrile DG templates in which nitrile group either directly connected to ortho-position or meta-substituted benzylic carbon of the phenyl ring, while, $N$-heteroaryl groups such as pyridine, pyrimidine, quinoline groups connected to another phenyl ring at ortho-position in $N$-heteroaryl DG templates. However, many of these aromatic DG templates associated with some limitations especially in their preparations such as i) multi-step (2-6 steps) synthesis, ii) using of TM-catalysis and harsh condition steps for the template synthesis, iii) scalability, iv) easy installation and subsequent removal, v) recyclability, and vi) cost-effective. Moreover, harsh reaction conditions are required to activate the aryl inert $\mathrm{C}-\mathrm{H}$ bond.

To overcome these limitations, we sought new templates that would direct remote meta- $\mathrm{C}-\mathrm{H}$ functionalization. Therefore, from the viewpoint of synthetic practicality, the design and development of easily accessible, more efficient and economically feasible removable/recyclable directing group templates are highly desirable and extremely challenging. In this context, to the continuation of our endeavors towards $\mathrm{C}-\mathrm{H}$ functionalization reactions, ${ }^{17}$ herein, we describe the development of first aliphatic template 2-cyano-2-isobutyl-4methylpentanoic acid as removable DG in promoting high meta-selective and stereoselective oxidative $\mathrm{C}-\mathrm{H}$ olefination of alcohol-based substrates using Pd-catalyst to generate valuable meta-olefinated aromatic compounds in good to excellent isolated yields. The designed nitrile template can be easily synthesized in a multi-gram scale from commercially available inexpensive starting material methyl cyanoacetate (20) using simple acid/base chemistry without column chromatography purification in two steps at room temperature.

\section{Results and discussions:}

We envisioned that the use of simple cyanoacetic acid ester of aryl substituted alcohol may serve as the best choice for activation of a distal meta-C-H bond of aryl alcohol scaffolds through linear "end-on" coordinating nitrile group. According$1 y$, in our first design towards developing a practical aliphatic DG template, we used a simple cyanoacetic acid as the template tethered to benzyl alcohol and 2-phenylethanol to provide esters $\mathbf{1 a}$ and $\mathbf{1 b}$ as the substrates for testing metaselective $\mathrm{C}-\mathrm{H}$ activation. Disappointingly, no or trace amount of olefinated product was observed under previously established reaction conditions, which may be due to conjugation of nitrile group with active methylene protons (Table 1, entries 1 $\& 2$ ). We further hypothesized that geminal dialkyl groups at the active methylene position of the cyanoacetate might serve as blocking groups to improve the meta-directing ability of the template. Therefore, we introduced two methyl groups at $\alpha$ position to the nitrile directing group to obtain substrate 2 . We were grateful to find that the methyl-substituted template gave a readily separable mixture of mono-olefinated $\mathbf{1 2}_{\text {mono }}$ ( $m$ :others, 92:8) and di-olefinated $\mathbf{1 2}_{\text {di }}$ products in $76 \%$ combined yield (Table 1, entry 3 ). From this experiment, we also confirmed that the presence of alkyl groups as blocking groups on the template at the active methylene position was essential for reactivity. Both meta-selectivity and yield of products gradually improved as the increasing size of the alkyl groups from methyl (2) to the isobutyl group (5a) (Table 1, entries 2$6)$. However, the regioselectivity of only mono olefination product (14) was found to be 91:9 ( $m$ :others) when sterically bulky $n$-heptyl blocking groups were used on the template, but the yield of the product significantly dropped to $12 \%$, which might be due to high steric crowding of the bulky $n$-heptyl groups (Table 1, entry 5). The use of secondary alkyl groups was not beneficial to improve the yield and selectivity (Table 1 , entries $7 \& 8$ ). The substrates of cycloalkyl-based templates $\mathbf{8}$ and 9 provided comparable results to product 13 with respect to the yield and the meta-selectivity (Table 1 , entries $9 \& 10$ ). Using 2-cyano-2-isobutyl-4-methylpentanoic acid as the optimal template, we further scrupulously evaluated various parameters including solvent, ligand, catalyst, temperature and mole ratio, we found that the treatment of 5a with ethyl acrylate 10a (2 equiv) in the presence of $\mathrm{Pd}(\mathrm{OAc})_{2}(10 \mathrm{~mol} \%)$ as the catalyst, and Ac-Gly-OH $(20 \mathrm{~mol} \%)$ as the ligand, AgOAc ( 2 equiv) as the oxidant, in HFIP $(1 \mathrm{~mL})$ at $55{ }^{\circ} \mathrm{C}$ for $24 \mathrm{~h}$ (Table 1 , entry 6), provided the olefinated product $15 \mathbf{a a}$ in $77 \%$ yield with excellent meta-selectivity ( $m$ :others, 96:4).

Table 1. Screening of templates for meta-C-H olefination.

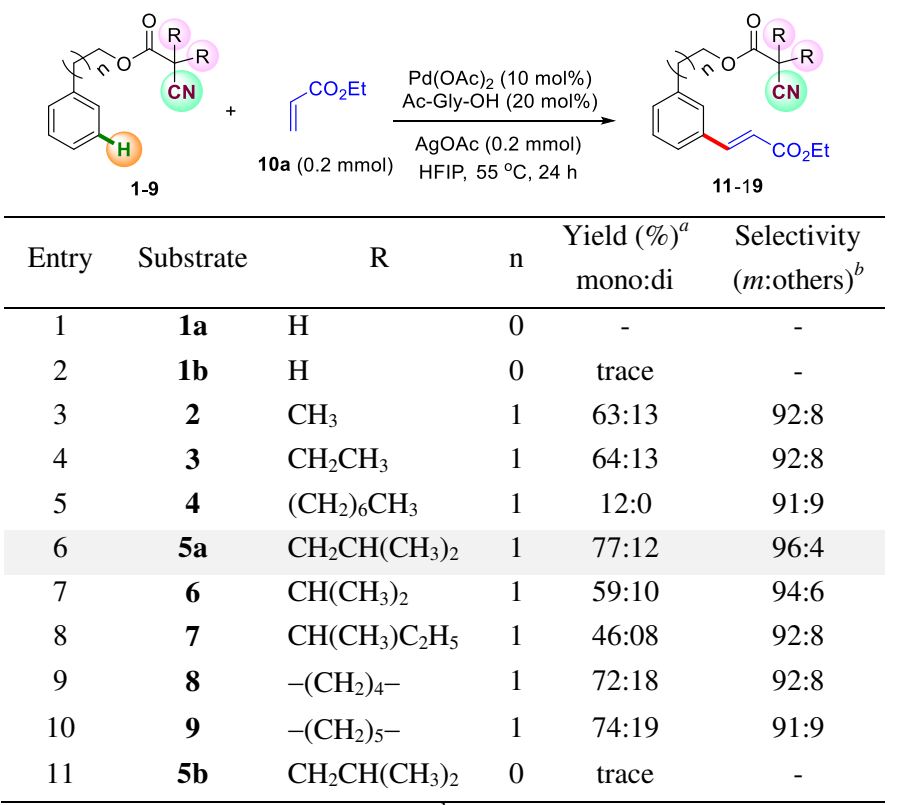

${ }^{a}$ Yields were determined by crude ${ }^{1} \mathrm{H}$ NMR analysis using $\mathrm{CH}_{2} \mathrm{Br}_{2}$ as the internal standard. ${ }^{b}$ Selectivity was determined by ${ }^{1} \mathrm{H}$ NMR analysis.

The designed removable aliphatic template $(\mathbf{2 3})$ can be easily synthesized in a multi-gram scale from readily available bench top and inexpensive starting materials in two steps using simple acid/base chemistry at room temperature (Scheme 1). Accordingly, active methylene group of methyl cyanoacetate (20) was dialkylated with 1-iodo-2methylpropane (21) by nucleophilic substitution bimolecular reaction in the presence of a base $\mathrm{K}_{2} \mathrm{CO}_{3}$ in DMF to provide compound (22), which on further base hydrolysis yielded the desired template (23) in excellent yield $(92 \%)$ over two steps. Remarkably, for over the two reaction steps to achieve $\mathbf{2 3}$ starting from 20, no column chromatography purification is required. The structure of the template $(\mathbf{2 3})$ was also confirmed by the single crystal X-ray diffraction analysis (see; Supporting Information). 


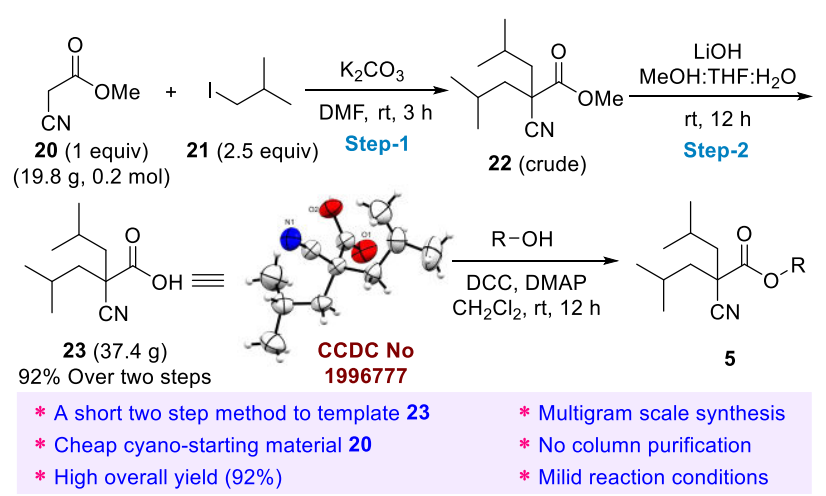

Scheme 1. Column chromatography free multi-gram scale synthesis of template $\mathbf{2 3}$ and its installation to give $\mathbf{5}$.

With this newly developed aliphatic template and optimal reaction conditions in hand (Table 1 , entry 6), meta-C- $\mathrm{H}$ olefination of extensive aryl substituted alcohol-based scaffolds was examined, which are shown in Table 2. To probe the electronic and steric influences on meta-olefination reaction, ethyl acrylate (10a) as the coupling partner was reacted with a diverse array of functionalized aryl carboxylic esters of nitrile template under standard conditions. With regard to orthosubstituted arenes, the reaction selectively achieved at a sterically less-hindered position with high levels of metaselectivity irrespective of substituent's electronic properties, thus delivering desired meta-olefinated products (15ca-15ea) in high yields. Likewise, both electron-donating such as methyl (5f) and electron-withdrawing substituents such as chloro $(\mathbf{5 g})$, and trifluoromethyl $(\mathbf{5 h})$ at the meta-position of arene substrates were olefinated at remaining meta-position, and corresponding mono-olefinated products (15fa-15ha) obtained predominantly in good yields. In addition, para-substituted arenes bearing methyl and methoxy were also viable substrates and delivered desired products (15ia) and (15ja), in 77\% and $84 \%$ yields, respectively. Notably, arenes bearing sensitive and valuable functional groups such as fluoro, chloro, and bromo substituents $(\mathbf{5 k}, \mathbf{5 l}, \& \mathbf{5 m})$ were also highly compatible substrates, which may enable further elaboration using classic metal-catalyzed cross-coupling reactions at the halogenated positions, especially, the products 15la and 15ma bearing $\mathrm{Cl}$ and $\mathrm{Br}$ substituents, respectively. Furthermore, the substitution of the benzylic position with a methoxy (5n) and cyclopentyl (5o) groups were also effective in the olefination reaction. In addition to the 2-phenylethanols, one carbon homologation primary alcohol (5p) was also amenable to olefination reaction. Further, secondary alcohols derived substrates $(\mathbf{5 q} \& \mathbf{5 r})$ were smooth in the reaction with almost equal efficacy. Moreover, phenol (5s) and benzyl alcohol (5t) derivatives also reacted efficiently to give the corresponding olefinated products (15sa) and (15ta) in 75\% and 67\% yields, respectively. It should be noted that 1-naphthalene alcohol (5u) was also amenable to the meta-olefination, which proceeded with remarkable meta-selectivity at the moreaccessible 3-position of the bicyclic ring. Notably, when 2,2diphenylethanol scaffold $(\mathbf{5} \mathbf{v})$ was engaged as a substrate in the reaction, only one of the phenyl rings was olefinated (15va) and yielded the product in 65\% yield. The template derived from ortho-phenyl phenol substrate $(\mathbf{5 w})$ was also olefinated at the remote-meta-position position of substituted phenyl ring as it's meta-position would be ideally situated to generate the appropriate 11-membered palladacycle or 12membered bimetallic cycle. Whereas the template connected aryl ring's meta-position would generate only 8 -membered palladacycle or 9-membered bimetallic cycle that must be highly unlikely to form due to severe strain associated with it.

Table 2. Scope of aryl substituted alcohol-based scaffolds for meta-C-H olefination. ${ }^{a, b}$
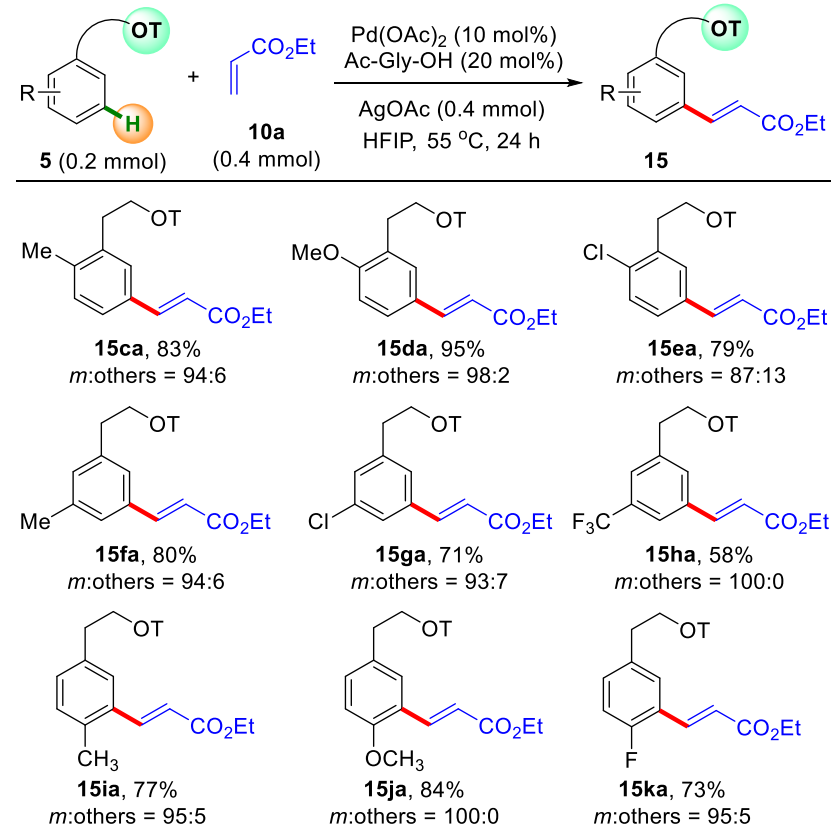

15ea, $79 \%$ $m$ :others $=93: 7$
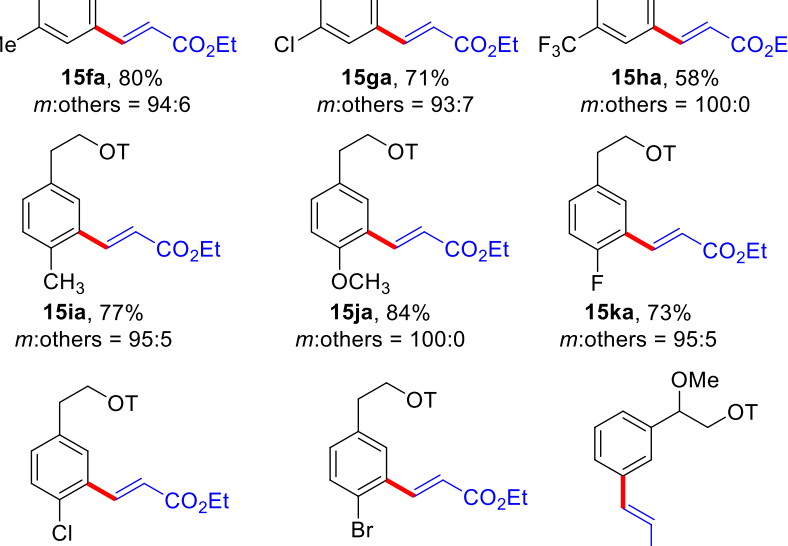

$m$ :others

15ja, 84 $m:$ others $=100: 0$

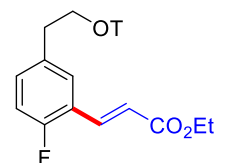

15ka, 73\%

$15 \mathrm{ka}, 73 \%$
$m$ :others $=95: 5$

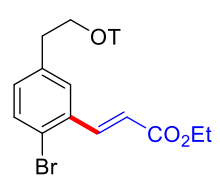

15la, $69 \%$

$m$ :others $=98: 2$

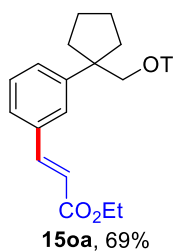

$15 \mathrm{ma}, 65 \%$ $m:$ others $=89: 11$
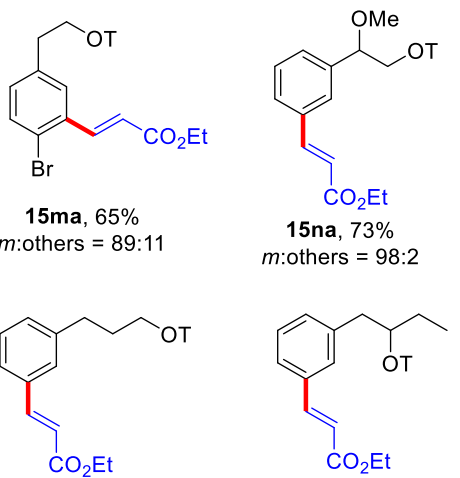

$m:$ others $=100: 0$

15pa $72 \%$

$m$ :others $=93: 7$

$15 q a, 70 \%$

$m$ :others $=96: 4$
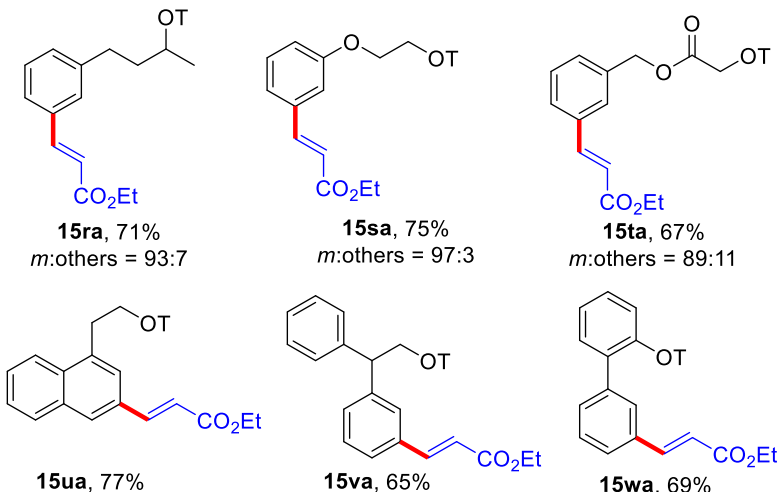

15ua, $77 \%$

$m:$ others $=98: 2$

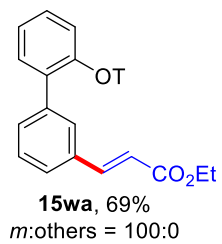

${ }^{a}$ Yields of isolated products on a $0.2 \mathrm{mmol} \mathrm{scale.}{ }^{b}$ Selectivity was determined by ${ }^{1} \mathrm{H}$ NMR analysis. 
Table 3. Scope of alkenes for meta-C-H olefination ${ }^{a, b}$
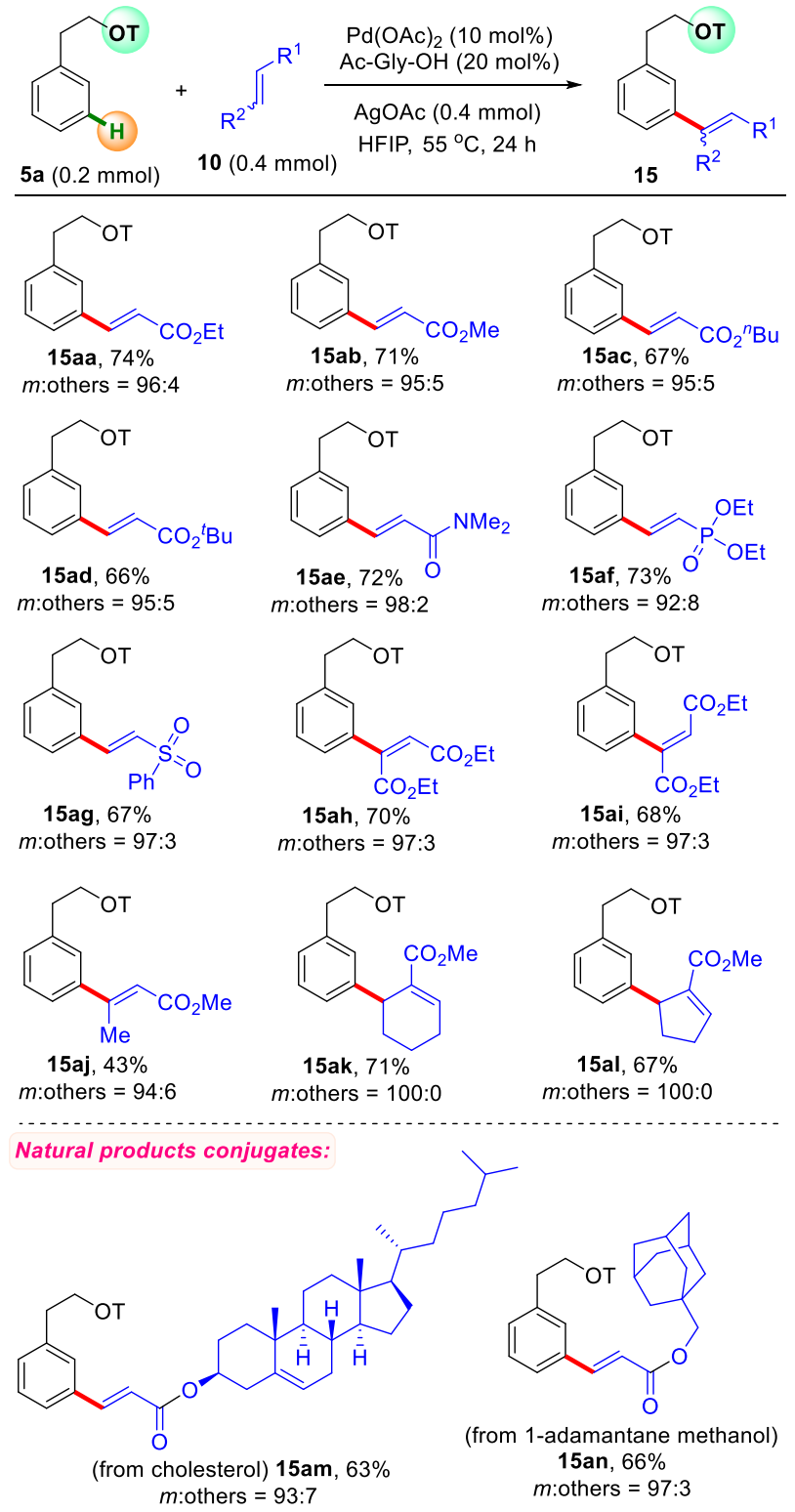

${ }^{a}$ Yields of isolated products on a $0.2 \mathrm{mmol}$ scale. ${ }^{b}$ Selectivity was determined by ${ }^{1} \mathrm{H}$ NMR analysis.

To further illustrate the synthetic utility of this protocol, $m e$ ta-olefination of simple phenyl substrate (5a) with a wide range of olefins as coupling partners was investigated (Table $3)$. To our great delight, meta-selective olefination with a variety of commonly used electron-deficient terminal olefins such as acrylates (10a-10d), N,N-dimethylacrylamide (10e), vinyl phosphonate (10f) and vinyl sulfone (10g) underwent smoothly to render the synthetically useful functionalized products in good chemical yields with exquisite stereo- and meta-selectivities. The present strategy can also be applied to di-substituted internal olefins including diethyl fumarate $(\mathbf{1 0 h})$, diethyl maleate $(\mathbf{1 0 i})$ and trans-methyl crotonate $(\mathbf{1 0 j})$ afforded tri-substituted olefin products (15ah-15aj) stereospecifically; however, internal-olefins are usually difficult to compatible with directed $\mathrm{C}-\mathrm{H}$ olefination reactions. To our delight, the reaction was also highly compatible with more challenging tri-substituted cyclic olefins (10k and 10l) and provided a good yield of meta-allylated products 15ak and 15al with outstanding meta-selectivity. In contrast, the anticipated meta-olefinated product was not observed when acrylonitrile and styrene were used as an olefin counterpart. Furthermore, acrylates derived from structurally complex natural products including cholesterol, and 1-adamantane methanol proceeded smoothly to produce the corresponding olefinated products 15am and 15an in good yields with excellent regioselectivity.

Table 4. Scope of homo and hetero-meta-selective bisolefination $^{a, b}$
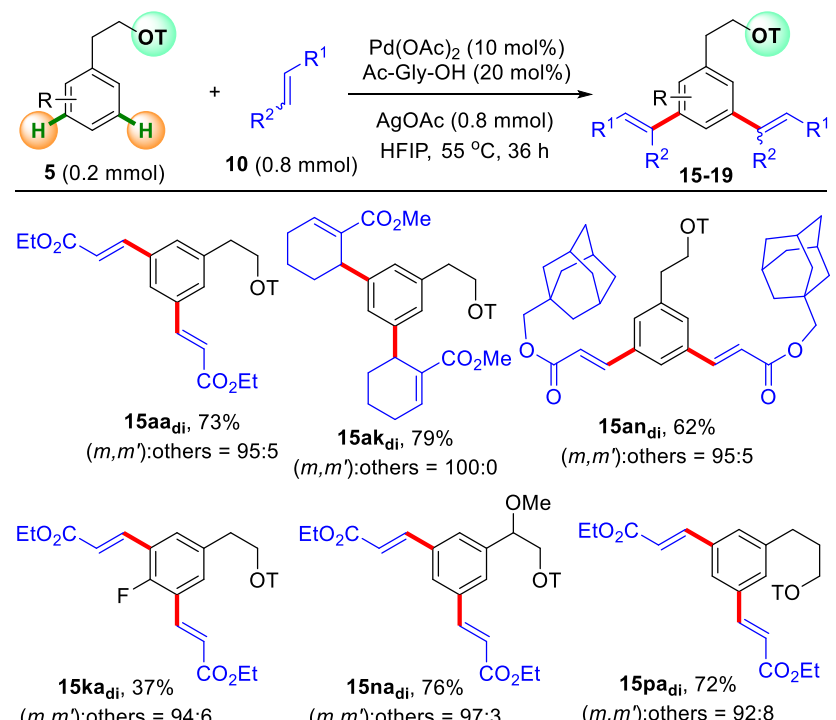

$\left(m, m^{\prime}\right)$ :others $=94: 6 \quad\left(m, m^{\prime}\right)$ :others $=97: 3 \quad\left(m, m^{\prime}\right)$ :others $=92: 8$
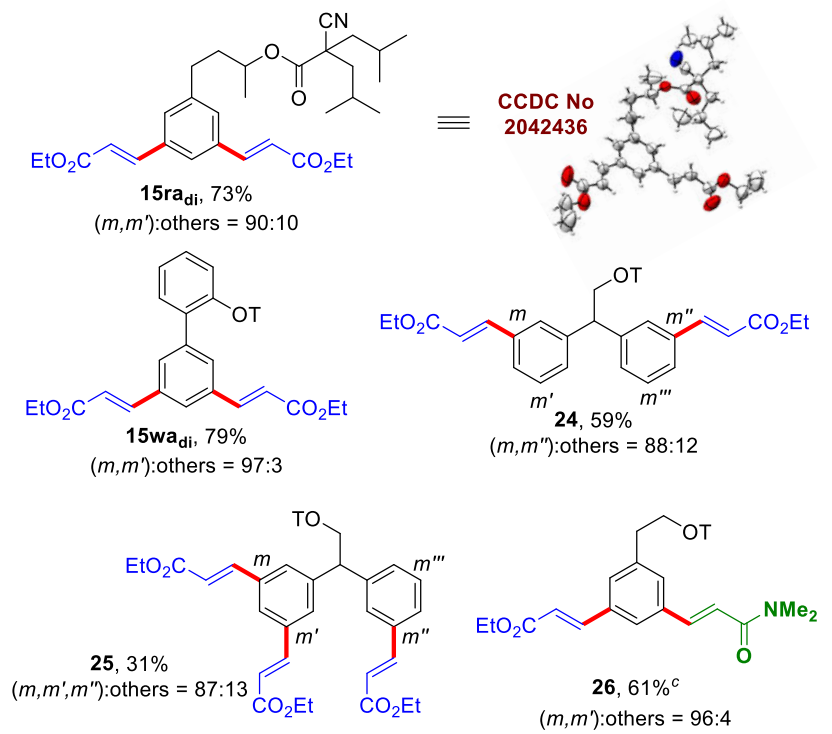

${ }^{a}$ Yields of isolated products on a $0.2 \mathrm{mmol}$ scale. ${ }^{b}$ Selectivity was determined by ${ }^{1} \mathrm{H}$ NMR analysis. ${ }^{c} \mathbf{1 0}(0.4 \mathrm{mmol})$, AgOAc $(0.4$ mmol.

These significant results encourage us to generate symmetrical and unsymmetrical two-fold $\mathrm{C}-\mathrm{H}$ olefinated products since they are extensively used as efficient precursors in materials research, synthetic chemistry, and particularly beneficial for drug discovery. Traditionally dihaloarenes were employed as the precursors in Mizoroki-Heck reaction for the synthesis of such bis-olefinated scaffolds. ${ }^{18}$ However, when increasing the amount of both the olefin (4 equiv) as the coupling partner 
and $\mathrm{AgOAc}$ (4 equiv) as the oxidant, with respect to 1 equiv of arene substrate, two olefin coupling partners could be expediently introduced in a site-selective fashion to deliver symmetrical bis-olefinated products in excellent yields as shown in Table 4. In order to obtain unsymmetrical bis-olefination product (26), mono-olefinated products have been employed as the starting materials. Therefore, the synthesis of bisolefinated products indicated that the present aliphatic nitrile template is indeed very reactive and effective under the optimal condition for sequential meta- $\mathrm{C}-\mathrm{H}$ olefination.

To demonstrate the efficiency, operational simplicity and practicality of this newly developed aliphatic templatedirected meta-C-H olefination, the gram-scale reaction was carried out using 5d as the model substrate under optimized reaction conditions. Pleasingly, a negligible deviation in the yield $(91 \%)$ was observed (Scheme 2 ).
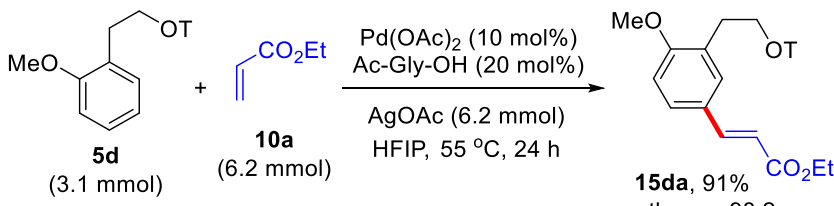

Scheme 2. Gram-Scale Synthesis.

Furthermore, we performed an intermolecular competition study between electron-rich methoxy and electron-deficient chloro substituents at para-position of the phenyl ring of arene templates. The yield ratio of products (1.3:1) indicates that a rate of reaction for electron-rich substituted arenes is slightly faster than the electron-poor substituted arenes (Scheme 3). This can be reasoned that electron rich arenes would chelate with palladium catalyst at a relatively faster rate when compared that of electron deficient ones.
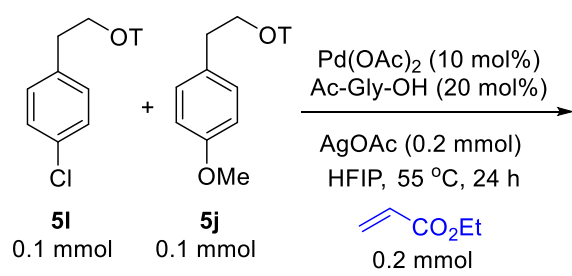

Scheme 3. Intermolecular competition experiment.

A control experiment revealed that the nitrile group is indispensable for this reaction, as only a small amount of a mixture of olefination products was detected, when nitrile template free substrate $\mathbf{2 7}$ was subjected to the reaction with ethyl acrylate 10a, which indicates the complete loss of reactivity and selectivity without nitrile as a directing group (Scheme 4).

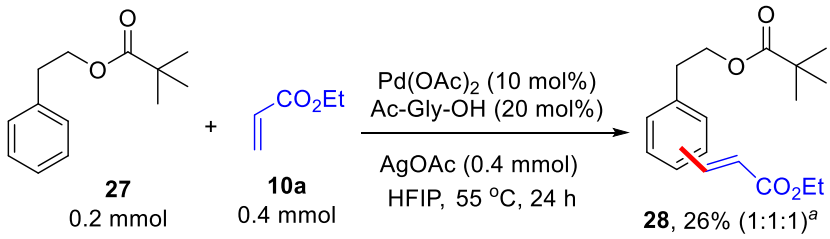

Scheme 4. Control experiment. ${ }^{a}$ Yield and selectivity of $\mathbf{2 8}$ was determined from crude ${ }^{1} \mathrm{H}$ NMR analysis.

Additionally, the easy removal and quantitative recovery of the aliphatic nitrile template can be performed through the base hydrolysis of the meta-olefinated substrate using $\mathrm{LiOH}$ (Scheme 5).

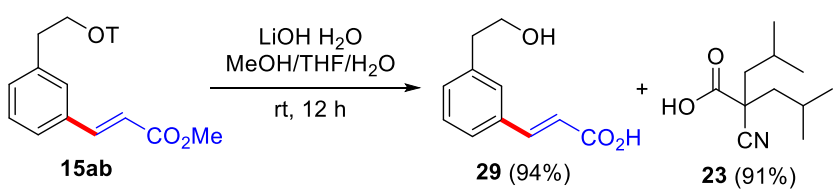

Scheme 5. Removal and recycling of the template.

\section{Computational Studies:}

Methodology: Gaussian $09^{18}$ was used for all calculations. We optimized all the structures at the hybrid functional, B3LYP ${ }^{19}$ level of density functional theory. LANL2DZ ${ }^{20}+\mathrm{f}(1.472)$ basis set with effective core potential (ECP) was used for $\mathrm{Pd}$, and LANL2DZ+f (1.611) with ECP was employed for Ag. 6$31 \mathrm{G}(\mathrm{d})^{21}$ was used for all other atoms. The frequency analysis with no negative confirmed the saddle points of optimized structures and transition states have only one negative frequency. The transition states in the mechanistic path were computed through the Synchronous Transit-Guided QuasiNewton method (STQN) ${ }^{22}$ method. The transition states were confirmed by performing intrinsic reaction coordinates (IRC) calculations by connecting respective minima. The single point energies were refined for all the optimized structures at meta-GGA exchange functional $\mathrm{M}^{23} 6^{23} / \mathrm{SDD}^{24}$ (for metal atoms)/6-311++G (d, p) level. The effect of solvent was considered through the $\mathrm{SMD}^{25}$ model for the single point calculations by using 1,1,1,3,3,3 hexafluoro isopropanol (HFIP) as the solvent with dielectric constant $=15.7$. All the thermochemistry calculations were performed at the experimental temperature $328.15 \mathrm{~K}$. The free energy, and the enthalpy corrections are taken at B3LYP level. The reaction free energies were calculated by adding the free energy correction at B3LYP/LANL2DZ/6-31G(d) level and change in solvation free energy to the electronic energy at the M06 level. The reaction enthalpies were obtained by the sum of the electronic energy with the enthalpy correction and with solvation enthalpy. Natural bond orbital (NBO) ${ }^{26}$ analyses were performed at the M06/SDD (for metal atoms)/6-311++G(d,p)( for the other atoms) including Wiberg bond indices (WBIs). We explored the mechanism of the catalytic process by two ways involving mononuclear Pd and bimetallic Pd-Ag complexes for a comparison. However, the experimental procedures involve later complexes for the catalytic steps. 

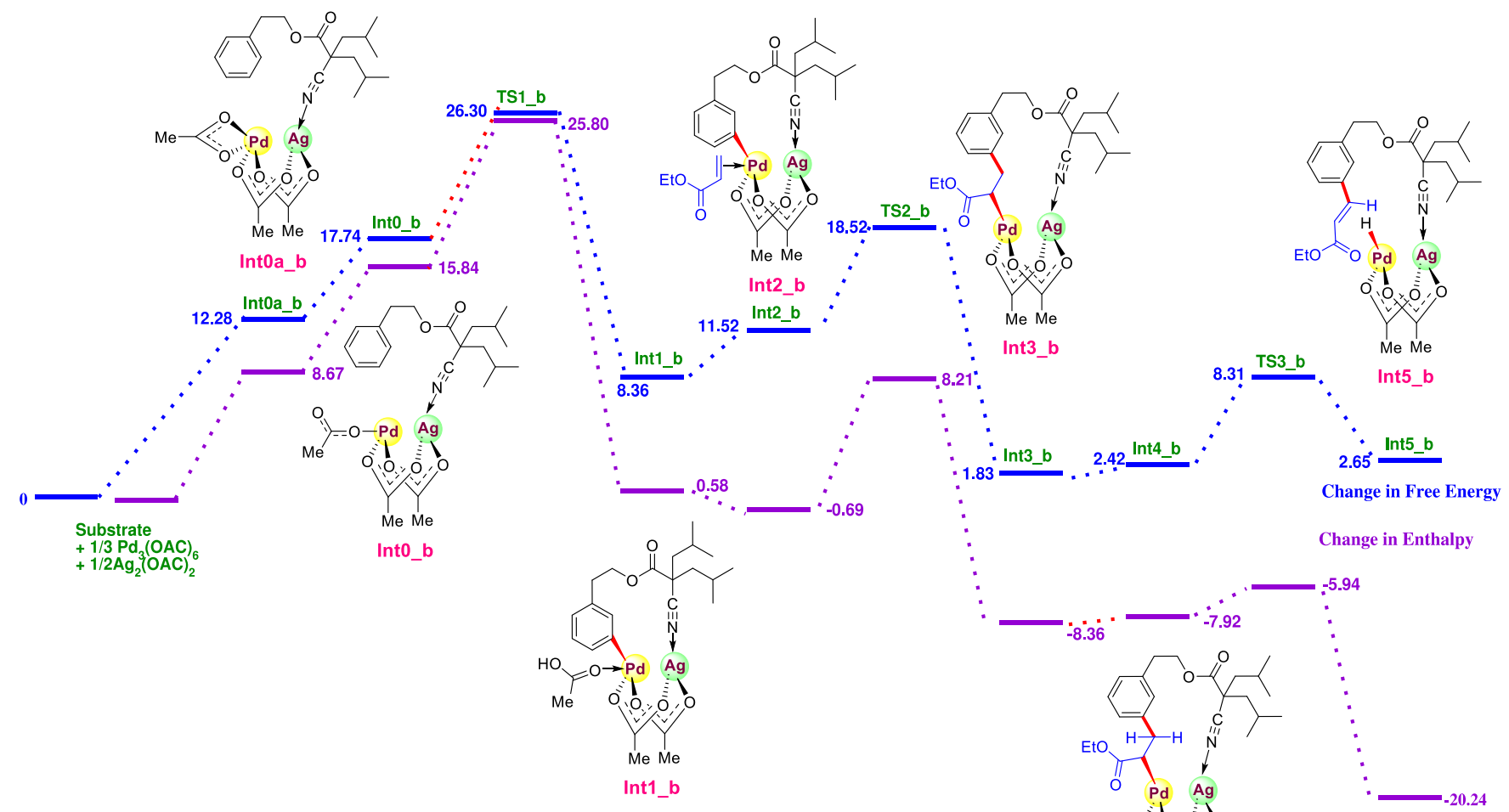

\section{$\mathrm{C}-\mathrm{H}$ activation}

Alkene insertion

$\beta$-hydride elimination

Figure 2. Top: Detailed mechanism of meta-C-H activation catalyzed by the $\mathrm{Pd}_{3}(\mathrm{OAc})_{6}$ and $\mathrm{Ag}_{2}(\mathrm{OAc})_{2}$. Bottom: The energy profile computed at the B3LYP/ LANL2DZ+f (Pd,Ag)/ 6-31G(d) (for other), M06/SDD (for metal atoms)/6-311++G(d,p).

meta-C-H activation by the bimetallic Pd-Ag complex: The pre-catalyst in this mechanism is a trimeric complex, and it can be initiated to form the dimeric and monomeric forms. The catalytic process of the reaction involves a $\mathrm{Pd}-\mathrm{Ag}$ heterodimeric complexes with the introduction of $\mathrm{Ag}(\mathrm{OAc})_{2}$. The distance between $\mathrm{Pd}-\mathrm{Ag}$ atoms was found to be $2.90 \AA$, which is smaller than the sum of the van der Waals radii ${ }^{27}$ of the $\mathrm{Pd}$ and $\mathrm{Ag}$ atoms. The mechanism of meta-C$-\mathrm{H}$ bond activation was studied in three steps like earlier, according to Scheme 1, and the free energy profile is shown in Figure 2. The nitrogen of nitrile group is bonded with $\mathrm{Ag}$, and the $\mathrm{Pd}$ and $\mathrm{Ag}$ atoms are connected through the acetate groups in the intermediate Int0a_b, which has $12.28 \mathrm{kcal} \mathrm{mol}^{-1}$ higher free energy than the initial reactants. This intermediate is converted to the Int0_b by moving one of the acetate groups on $\mathrm{Pd}$. The natural charges on both metal atoms are nearly equal to 0.70 ( 0.7077 for $\mathrm{Pd}$ and 0.6956 for $\mathrm{Ag}$ ), and on the meta carbon atom, it is $-0.1905 \mathrm{e}$. The $\mathrm{Ag}-\mathrm{N}$ bond length is $2.25 \AA$. The formation Int0_b requires the free energy of $17.74 \mathrm{kcal} \mathrm{mol}^{-1}$. The meta- $\mathrm{C}-\mathrm{H}$ bond is broken and $\mathrm{Pd}-\mathrm{C}$ (aromatic ring) bond is formed; this bond leads to the formation of intermediate Int1_b. The $\mathrm{Pd}-\mathrm{C}$ bond distance is $1.98 \AA$ and the WBI changes to 0.7826 from 0.0011 . The conversion of Int0_b to Int1_b is occurred through the transition state TS1_b, with an activation free energy and enthalpies of 26.30 and $25.80 \mathrm{kcal}$ $\mathrm{mol}^{-1}$, respectively. This transition state is obtained by the transfer of hydrogen of the meta- $\mathrm{C}-\mathrm{H}$ bond to the acetate group and aromatic ring towards the $\mathrm{Pd}$ metal center. The corresponding transition state structure is shown in Figure 3 along with the IRC (Figure 3A). In TS1_b, the partial charge on $\mathrm{Pd}(0.5758 \mathrm{e})$ decreases with the increase of charge on $\mathrm{Ag}$ (0.7370e) as compare to Int0_b. The WBI of $\mathrm{Pd}-\mathrm{C}$ bond changes from 0.0011 to 0.4077 (in TS1_b) and 0.7826 (in Int1_b). After activation of the $\mathrm{C}-\mathrm{H}$ bond, the alkene is introduced near to Pd metal center with the removal of the acetic acid, which leads to the formation of Int2_b. The formation of this intermediate requires $11.52 \mathrm{kcal} \mathrm{mol}^{-1}$. The alkene carbon atoms are at the same distance $(2.22 \AA)$ from the Pd. The $\alpha$ carbon forms the bond with the $\mathrm{Pd}$, and subsequently, the meta-carbon of the aromatic ring forms the bond with $\beta$ carbon of the alkene leading to the formation of Int3_b. The $\mathrm{Pd}-\mathrm{C}(\alpha)$ bond distance is $2.00 \AA$ and the WBI changes from 0.3113 to 0.6445 , which confirms the metal-carbon bond. The formation of Int3_b requires free energy of 1.83 and enthalpy of $-8.36 \mathrm{kcal} \mathrm{\textrm {mol } ^ { - 1 }}$. The conversion of Int2_b to Int3_b is happened through the transition state TS2_b (Figure 3) and verified with IRC calculations (Figure 3B). The activation free energy and activation enthalpies for this step are 18.52 and $8.21 \mathrm{kcal} \mathrm{mol}^{-1}$, respectively. The bond distance of $\mathrm{Pd}-\mathrm{C}(\alpha)$ is $2.14 \AA$, the WBI of this bond is 0.4388 and $C(\beta)-C$ bond distance is $2.61 \AA$. The natural charge at $\mathrm{Ag}$ increases to 0.7264 and on Pd atom decreases to 0.3977 . After the formation of the Int3_b, the hydrogen on the $\beta$-carbon orients towards Pd and forms an intermediate Int4_b with a free energy of $2.42 \mathrm{kcal} \mathrm{mol}^{-1}$. From this intermediate, the $\beta$ hydrogen is transferred to $\mathrm{Pd}$ and forms a covalent bond leading to the formation of Int5_b. The free energy for the formation of this is $2.65 \mathrm{kcal} \mathrm{mol}^{-1}$. The transition state TS3_b is involved with an activation free energy of $8.31 \mathrm{kcal} \mathrm{mol}^{-1}$. The WBI of Pd---H bond is 0.5031. In intermediate Int5_b, the WBI of $\mathrm{Pd}-\mathrm{C}$ bonds is less than 0.3 , which suggests the release of the product. 

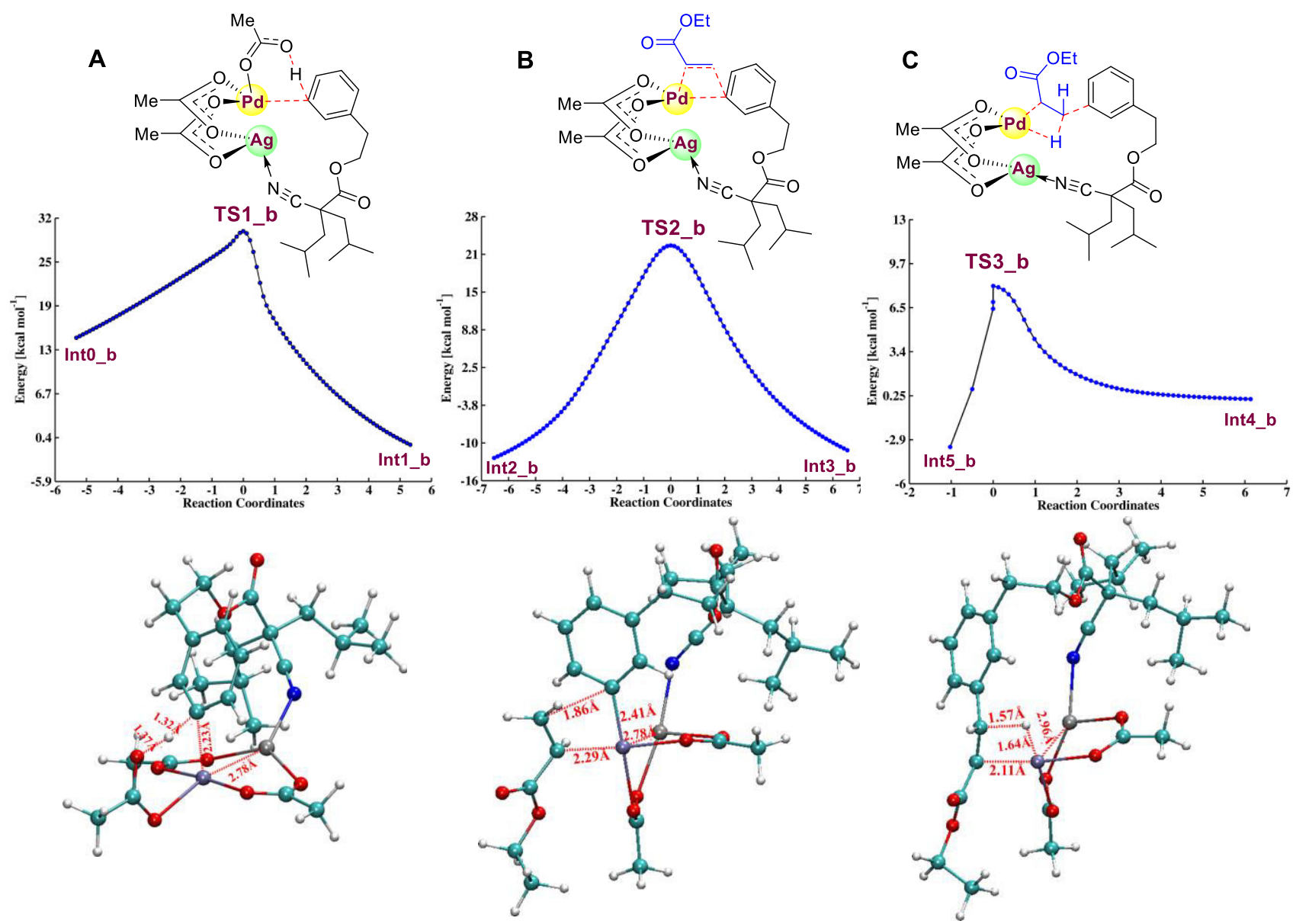

Figure 3. A, B and C represent the Intrinsic Reaction Coordinate (IRC) path for the meta-C-H activation, alkene insertion and $\beta$ hydride elimination, respectively. The corresponding transition states are shown in the same order.

By comparing all these three steps of the mechanism, the rate-determining step is the activation of the $\mathrm{C}-\mathrm{H}$ bond. By comparing both mechanistic pathways, the bimetallic pathway seems to be the less energetic pathway than the monomer one. The bond distances between Pd and Ag vary between 2.80 to $2.95 \AA$. During the progress of the reaction, the charge on the $\mathrm{Pd}$ atom decreases and $\mathrm{Ag}$ increases. From the WBI values (mostly near to 0.5 ) on the transition states, gives the evidence exchange of covalent bonds.

\section{Conclusion}

In summary, we have developed the first removable and simple aliphatic nitrile template as an effective DG template in promoting remote meta- $\mathrm{C}-\mathrm{H}$ bond olefination with good to excellent yields and excellent site-selectivity. The protocol is a highly efficient, economical and practical approach in achieving $\mathrm{C}-\mathrm{H}$ olefination at remote meta-position of the arenes under mild reaction conditions. Besides, double metaolefinated products can be also obtained in good yields. Moreover, the aliphatic template can be easily synthesized in a twostep synthetic sequence from readily available inexpensive methyl cyanoacetate, and is easily installed and removed/recycled. Other synthetic applications using this novel aliphatic nitrile template-directed meta-C $-\mathrm{H}$ activation strategy on various arene substrates (such as aryl substituted esters, phenol scaffolds, aniline based precursors, and heterocyclic based substrates) are currently under investigation in our laboratory.

\section{EXPERIMENTAL SECTION}

General procedure for the meta-lefinanation directed by a 2-cyano-2-isobutyl-4-methylpentanoic acid template.

An oven-dried $10 \mathrm{~mL}$ Schlenk-type sealed tube equipped with a magnetic stir bar was charged with the substrate $(0.2$ $\mathrm{mmol})$, olefin $(0.4 \mathrm{mmol}), \mathrm{Pd}(\mathrm{OAc})_{2}(10 \mathrm{~mol} \%)$, Ac-Gly-OH (20 mol\%), AgOAc (0.4 mmol), and hexafluoroisopropanol (HFIP) $(2 \mathrm{~mL})$, then the resulting mixture was heated in a 55 ${ }^{\circ} \mathrm{C}$ oil bath with rapid stirring for $24 \mathrm{~h}$. After cooling to room temperature, the reaction mixture was filtered through a pad of celite. The filtrate was concentrated and purified by silica gel column chromatography using hexane/EtOAc as the eluent to provide the desired meta-olefinated product.

\section{ASSOCIATED CONTENT}

Supporting Information. The Supporting Information is available free of charge on the ACS Publications website at DOI:...

Materials and methods, experimental procedures and compound characterization, mechanistic control experiments, computational studies, additional references, and select NMR spectra (PDF)

\section{AUTHOR INFORMATION}

\section{Corresponding Author}

*gvsatya@iith.ac.in

*bhabani@iith.ac.in

\section{ORCID}


Perla Ramesh: 0000-0002-3318-9896

Gedu Satyanarayana: 0000-0002-6410-5421

Notes

The authors declare no competing financial interest.

\section{ACKNOWLEDGMENT}

We greatly acknowledge the financial support from DST-SERB (Department of Science and Technology, Science and Engineering Research Board, Grant EMR/2017/005312), New Delhi. P.R. thanks DST-SERB for the award of National Postdoctoral Fellowship (Diary SERB/F/7226/2017-2018).

\section{REFERENCES}

(1) (a) Lyons, T. W.; Sanford, M. S. Palladium-Catalyzed LigandDirected C-H Functionalization Reactions. Chem. Rev. 2010, 110, 1147-1169. https://doi.org/10.1021/cr900184e. (b) Mkhalid, I. A. I.; Barnard, J. H.; Marder, T. B.; Murphy, J. M.; Hartwig, J. F. C-H Activation for the Construction of C-B Bonds. Chem. Rev. 2010, 110, 890-931. https://doi.org/10.1021/cr900206p. (c) Gutekunst, W. R. Baran, P. S. C-H Functionalization Logic in Total Synthesis. Chem. Soc. Rev. 2011, 40, 1976-1991. https://doi.org/10.1039/c0cs00182a. (d) Yamaguchi, J.; Yamaguchi, A. D.; Itami, K. C-H Bond Functionalization: Emerging Synthetic Tools for Natural Products and Pharmaceuticals. Angew. Chem., Int. Ed. 2012, 51, 8960-9009. https://doi.org/10.1002/anie.201201666. (e) Davies, H. M. L.; Morton, D. Recent Advances in C-H Functionalization. J. Org. Chem. 2016, 81, 343-350. https://doi.org/10.1021/acs.joc.5b02818.

(2) (a) Daugulis, O.; Do, H. Q.; Shabashov, D. Palladium- and Copper-Catalyzed Arylation of Carbon-Hydrogen Bonds. Acc. Chem. Res. 2009, 42, 1074-1086. https://doi.org/10.1021/ar9000058. (b) Tang, K. X.; Wang, C. M.; Gao, T. H.; Chen, L.; Fan, L.; Sun, L. P. Transition Metal-Catalyzed C-H Bond Functionalizations by Use of Sulfur-Containing Directing Groups. Adv. Synth. Catal. 2019, 361 , 26-38. https://doi.org/10.1002/adsc.201800484. (c) Liu, J.; Zheng, L. Recent Advances in Transition-Metal-Mediated Chelation- Assisted Sulfonylation of Unactivated C-H Bonds. Adv. Synth. Catal. 2019 , 361, 1710-1732. https://doi.org/10.1002/adsc.201801307. (d) Colby, D. A.; Bergman, R. G.; Ellman, J. A. Rhodium-Catalyzed C-C Bond Formation via Heteroatom-Directed $\mathrm{C}-\mathrm{H}$ Bond Activation. Chem. Rev. 2010, 110, 624-655. https://doi.org/10.1021/cr900005n. (e) De Sarkar, S.; Liu, W.; Kozhushkov, S. I.; Ackermann, L. Weakly Coordinating Directing Groups for Ruthenium(II)-Catalyzed C-H Activation. Adv. Synth. Catal. 2014, 356, 1461-1479. https://doi.org/10.1002/adsc.201400110. (f) Yadav, M. R.; Rit, R. K.; Shankar, M.; Sahoo, A. K. Reusable and Removable Directing Groups for $\mathrm{C}\left(\mathrm{Sp}^{2}\right)-\mathrm{H}$ Bond Functionalization of Arenes. Asian J. Org. Chem. 2015, 4, 846-864. https://doi.org/10.1002/ajoc.201500105. (g) Sharma, R.; Thakur, K.; Kumar, R.; Kumar, I.; Sharma, U. Distant CH Activation/Functionalization: A New Horizon of Selectivity beyond Proximity. Catal. Rev. Sci. Eng. 2015, 57, 345-405. https://doi.org/10.1080/01614940.2015.1058623. (h) Sun, H.; Guimond, N.; Huang, Y. Advances in the Development of Catalytic Tethering Directing Groups for C-H Functionalization Reactions. Org. Biomol. Chem. 2016, 14, 8389-8397. https://doi.org/10.1039/c6ob01258b. (i) Sharma, R.; Sharma, U. Remote C-H Bond Activation/Transformations: A Continuous Growing Synthetic Tool; Part II. Catal. Rev. Sci. Eng. 2018, 60, 497-565. https://doi.org/10.1080/01614940.2018.1474538. (j) Rej, S.; Chatani, N. Rhodium-Catalyzed $\mathrm{C}\left(\mathrm{Sp}^{2}\right)-$ or $\mathrm{C}\left(\mathrm{Sp}^{3}\right)-\mathrm{H}$ Bond Functionalization Assisted by Removable Directing Groups. Angew. Chem., Int. Ed. 2019, 58, 8304-8329. https://doi.org/10.1002/anie.201808159. (k) $\mathrm{Xu}, \mathrm{X}$.; Luo, J. Transition-metal-catalyzed Directing Group-Assisted $\mathrm{C}-\mathrm{H}$ Activation of Phenols. ChemSusChem 2019. https://doi.org/10.1002/cssc.201901951.

(6) (a) Ackermann, L.; Vicente, R.; Kapdi, A. R. TransitionMetal-Catalyzed Direct Arylation of (Hetero)Arenes by $\mathrm{C}-\mathrm{H}$ Bond Cleavage. Angew. Chem., Int. Ed. 2009, 48, 9792-9826 https://doi.org/10.1002/anie.200902996. (b) Shi, G.; Zhang, Y. Carboxylate-Directed C-H Functionalization. Adv. Synth. Catal. 2014,
356, 1419-1442. https://doi.org/10.1002/adsc.201400028. (c) Ackermann, L. Carboxylate-Assisted Ruthenium-Catalyzed Alkyne Annulations by C-H/Het-H Bond Functionalizations. Acc. Chem. Res. 2014, 47, 281-295. https://doi.org/10.1021/ar3002798. (d) Zhao, D.; Vásquez-Céspedes, S.; Glorius, F. Rhodium(III)-Catalyzed Cyclative Capture Approach to Diverse 1-Aminoindoline Derivatives at Room Temperature. Angew. Chemie., Int. Ed. 2015, 54, 1657-1661. https://doi.org/10.1002/anie.201410342. (e) Kinuta, H.; Tobisu, M.; Chatani, N. Rhodium-Catalyzed Borylation of Aryl 2-Pyridyl Ethers through Cleavage of the Carbon-Oxygen Bond: Borylative Removal of the Directing Group. J. Am. Chem. Soc. 2015, 137, 1593-1600. https://doi.org/10.1021/ja511622e. (f) Chen, X.; Engle, K. M.; Wang, D. H.; Jin-Quan, Y. Palladium(II)-CataIyzed C-H Aetivation/C-C Cross-Coupling Reactions: Versatility and Practicality. Angew. Chem., Int. Ed. 2009, 48, 5094-5115. https://doi.org/10.1002/anie.200806273. (g) Ackermann, L. Carboxylate-Assisted Transition-Metal-Catalyzed C-H Bond Functionalizations: Mechanism and Scope. Chem. Rev. 2011, 111, 1315-1345. https://doi.org/10.1021/cr100412j. (h) Sun, C. L.; Li, B. J.; Shi, Z. J. Direct C-H Transformation via Iron Catalysis. Chem. Rev. 2011, 111, 1293-1314. https://doi.org/10.1021/cr100198w. (i) Yeung, C. S.; Dong, V. M. Catalytic Dehydrogenative Cross-Coupling: Forming Carbon-Carbon Bonds by Oxidizing Two Carbon-Hydrogen Bonds. Chem. Rev. 2011, 111, 1215-1292. https://doi.org/10.1021/cr100280d. (j) Arockiam, P. B.; Bruneau, C.; Dixneuf, P. H. Ruthenium(II)-Catalyzed C-H Bond Activation and Functionalization. Chem. Rev. 2012, 112, 5879-5918. https://doi.org/10.1021/cr300153j. (k) Neufeldt, S. R.; Sanford, M. S. Controlling Site Selectivity in Palladium-Catalyzed C-H Bond Functionalization. Acc. Chem. Res. 2012, 45, 936-946. https://doi.org/10.1021/ar300014f. (1) Giri, R.; Thapa, S.; Kafle, A. Palladium-Catalysed, Directed C-H Coupling with Organometallics. Adv. Synth. Catal. 2014, 356, 1395-1411. https://doi.org/10.1002/adsc.201400105.

(7) (a) Frost, C. G.; Paterson, A. J. Directing Remote Meta-C-H Functionalization with Cleavable Auxiliaries. ACS Cent. Sci. 2015, 1 , 418-419. https://doi.org/10.1021/acscentsci.5b00358. (b) Dey, A.; Agasti, S.; Maiti, D. Palladium Catalysed: Meta -C-H Functionalization Reactions. Org. Biomol. Chem. 2016, 14, 5440-5453. https://doi.org/10.1039/c6ob00395h. (c) Li, J.; De Sarkar, S.; Ackermann, L. Meta-and Para-Selective C-H Functionalization by C-H Activations. In Topics in Organometallic Chemistry; Springer Verlag, 2016; Vol. 55, pp 217-258. https://doi.org/10.1007/3418_2015_130. (d) Li, G. Directed Meta -Selective C H Bond Functionalizations. In Strategies for Palladium-Catalyzed Non-Directed and Directed $\mathrm{C}-\mathrm{H}$ Bond Functionalization; Elsevier, 2017; pp 289-325. https://doi.org/10.1016/b978-0-12-805254-9.00008-6. (e) Dey, A.; Sinha, S. K.; Achar, T. K.; Maiti, D. Accessing Remote Meta- and Para- $\mathrm{C}\left(\mathrm{Sp}^{2}\right)-\mathrm{H}$ Bonds with Covalently Attached Directing Groups. Angew. Chem., Int. Ed. 2019, 58, 10820-10843. https://doi.org/10.1002/anie.201812116.

(8) (a) Saidi, O.; Marafie, J.; Ledger, A. E. W.; Liu, P. M.; Mahon, M. F.; Kociok-Köhn, G.; Whittlesey, M. K.; Frost, C. G. RutheniumCatalyzed Meta Sulfonation of 2-Phenylpyridines. J. Am. Chem. Soc 2011, 133, 19298-19301. https://doi.org/10.1021/ja208286b. (b) Teskey, C. J.; Lui, A. Y. W.; Greaney, M. F. Ruthenium-Catalyzed Meta-Selective C-H Bromination. Angew. Chem., Int. Ed. 2015, 54, 11677-11680. https://doi.org/10.1002/anie.201504390. (c) Leitch, J. A.; Frost, C. G. Ruthenium-Catalysed $\sigma$-Activation for Remote: Meta -Selective C-H Functionalisation. Chem. Soc. Rev. 2017, 46, 71457153. https://doi.org/10.1039/c7cs00496f. (d) Khan, F. F.; Sinha, S. K.; Lahiri, G. K.; Maiti, D. Ruthenium-Mediated Distal C-H Activation. Chem. Asian J. 2018, 13, 2243-2256. https://doi.org/10.1002/asia.201800545. (e) Jia, C.; Wu, N.; Cai, X.; Li, G.; Zhong, L.; Zou, L.; Cui, X. Ruthenium-Catalyzed MetaSelective CAr-H Bond Formylation of Arenes. J. Org. Chem. 2020, 85, 4536-4542. https://doi.org/10.1021/acs.joc.0c00007. (f) Gandeepan, P.; Koeller, J.; Korvorapun, K.; Mohr, J.; Ackermann, L. Visible-Light-Enabled Ruthenium-Catalyzed Meta-C-H Alkylation at Room Temperature. Angew. Chem., Int. Ed. 2019, 58, 9820-9825. https://doi.org/10.1002/anie.201902258. (g) Sagadevan, A.; Greaney, 
M. F. Meta-Selective C-H Activation of Arenes at Room Temperature Using Visible Light: Dual-Function Ruthenium Catalysis. Angew. Chem., Int. Ed. 2019, 58, 9826-9830. https://doi.org/10.1002/anie.201904288. (h) Fan, Z.; Bay, K. L.; Chen, X.; Zhuang, Z.; Park, H. S.; Yeung, K.-S.; Houk, K. N.; Yu, J.Q. Rational Development of Remote $\mathrm{C}-\mathrm{H}$ Functionalization of Biphenyl: Experimental and Computational Studies. Angew. Chem., Int. Ed. 2020, 59, 4770-4777. https://doi.org/10.1002/anie.201915624.

(9) Leow, D.; Li, G.; Mei, T. S.; Yu, J. Q. Activation of Remote Meta-C-H Bonds Assisted by an End-on Template. Nature 2012, 486, 518-522. https://doi.org/10.1038/nature11158.

(10) (a) Bera, M.; Modak, A.; Patra, T.; Maji, A.; Maiti, D. Meta Selective Arene C-H Bond Olefination of Arylacetic Acid Using a Nitrile-Based Directing Group. Org. Lett. 2014, 16, 5760-5763. https://doi.org/10.1021/ol502823c. (b) Bera, M.; Maji, A.; Sahoo, S. K.; Maiti, D. Palladium(II)-Catalyzed Meta-C-H Olefination: Constructing Multisubstituted Arenes through Homo-Diolefination and Sequential Hetero-Diolefination. Angew. Chem., Int. Ed. 2015, 54, 8515-8519. https://doi.org/10.1002/anie.201503112. (c) Patra, T.; Watile, R.; Agasti, S.; Naveen, T.; Maiti, D. Sequential Meta-C-H Olefination of Synthetically Versatile Benzyl Silanes: Effective Synthesis of Meta-Olefinated Toluene, Benzaldehyde and Benzyl Alcohols. Chem. Commun. 2016, 52, 2027-2030. https://doi.org/10.1039/c5cc09446a. (d) Bera, M.; Sahoo, S. K.; Maiti, D. Room-Temperature Meta-Functionalization: Pd(II)-Catalyzed Synthesis of 1,3,5-Trialkenyl Arene and Meta-Hydroxylated Olefin. ACS Catal. 2016, 6, 3575-3579. https://doi.org/10.1021/acscatal.6b00675. (e) Maji, A.; Bhaskararao, B.; Singha, S.; Sunoj, R. B.; Maiti, D. Directing Group Assisted: Meta -Hydroxylation by C-H Activation. Chem. Sci. 2016, 7, 3147-3153. https://doi.org/10.1039/c5sc04060d. (f) Modak, A.; Mondal, A.; Watile, R.; Mukherjee, S.; Maiti, D. Remote Meta C-H Bond Functionalization of 2-Phenethylsulphonic Acid and 3-Phenylpropanoic Acid Derivatives. Chem. Commun. 2016, 52, 13916-13919. https://doi.org/10.1039/c6cc08302a.

(11) (a) Jayarajan, R.; Das, J.; Bag, S.; Chowdhury, R.; Maiti, D. Diverse Meta-C-H Functionalization of Arenes across Different Linker Lengths. Angew. Chem., Int. Ed. 2018, 57, 7659-7663. https://doi.org/10.1002/anie.201804043. (b) Achar, T. K.; Zhang, X.; Mondal, R.; Shanavas, M. S.; Maiti, S.; Maity, S.; Pal, N.; Paton, R. S.; Maiti, D. Palladium-Catalyzed Directed Meta-Selective $\mathrm{C}-\mathrm{H}$ Allylation of Arenes: Unactivated Internal Olefins as Allyl Surrogates. Angew. Chem., Int. Ed. 2019, 58, 10353-10360. https://doi.org/10.1002/anie.201904608. (c) Brochetta, M.; Borsari, T.; Bag, S.; Jana, S.; Maiti, S.; Porta, A.; Werz, D. B.; Zanoni, G.; Maiti, D. Direct Meta-C-H Perfluoroalkenylation of Arenes Enabled by a Cleavable Pyrimidine-Based Template. Chem. A Eur. J. 2019. 25, 10323-10327. https://doi.org/10.1002/chem.201902811. (d) Bag, S.; Petzold, M.; Sur, A.; Bhowmick, S.; Werz, D. B.; Maiti, D. Palladium-Catalyzed Selective Meta-C-H Deuteration of Arenes: Reaction Design and Applications. Chem.: Eur. J. 2019, 25, 9433-9437. https://doi.org/10.1002/chem.201901317. (e) Porey, S.; Zhang, X.; Bhowmick, S.; Kumar Singh, V.; Guin, S.; Paton, R. S.; Maiti, D. Alkyne Linchpin Strategy for Drug:Pharmacophore Conjugation: Experimental and Computational Realization of a Meta-Selective Inverse Sonogashira Coupling. J. Am. Chem. Soc. 2020, 142, 37623774. https://doi.org/10.1021/jacs.9b10646.

(12) Lee, S.; Lee, H.; Tan, K. L. Meta-Selective C-H Functionalization Using a Nitrile-Based Directing Group and Cleavable SiTether. J. Am. Chem. Soc. 2013, 135, 18778-18781. https://doi.org/10.1021/ja4107034.

(13) (a) Li, S.; Ji, H.; Cai, L.; Li, G. Pd(II)-Catalyzed Remote Regiodivergent Ortho- and Meta-C-H Functionalizations of Phenylethylamines. Chem. Sci. 2015, 6, 5595-5600. https://doi.org/10.1039/c5sc01737h. (b) Li, S.; Cai, L.; Ji, H.; Yang, L.; Li, G. Pd(II)-Catalysed Meta-C-H Functionalizations of Benzoic Acid Derivatives. Nat. Commun. 2016, 7. 10443 https://doi.org/10.1038/ncomms10443. (c) Yang, L.; Fu, L.; Li, G. Incorporation of Carbon Dioxide into Carbamate Directing Groups: Palladium-Catalyzed Meta-C-H Olefination and Acetoxylation of Aniline Derivatives. Adv. Synth. Catal. 2017, 359, 2235-2240. https://doi.org/10.1002/adsc.201700261. (d) Zhang, L.; Zhao, C.; Liu, Y.; Xu, J.; Xu, X.; Jin, Z. Activation of Remote Meta-C-H Bonds in Arenes with Tethered Alcohols: A Salicylonitrile Template. Angew. Chem., Int. Ed. 2017, 56, 12245-12249. https://doi.org/10.1002/anie.201705495.

(14) (a) Zhang, L.; Zhao, C.; Liu, Y.; Xu, J.; Xu, X.; Jin, Z. Activation of Remote Meta-C-H Bonds in Arenes with Tethered Alcohols: A Salicylonitrile Template. Angew. Chem., Int. Ed. 2017, 56, 1224512249. https://doi.org/10.1002/anie.201705495. (b) Tang, R. Y.; Li, G.; Yu, J. Q. Conformation-Induced Remote Meta-C-H Activation of Amines. Nature 2014, 507, 215-220. https://doi.org/10.1038/nature12963. (c) Wang, B.; Zhou, Y.; Xu, N.; $\mathrm{Xu}, \mathrm{X}$; Xu, X.; Jin, Z. Palladium(II)-Catalyzed Remote Meta-C-H Functionalization of Aromatic Tertiary Amines. Org. Lett. 2019, 21, 1885-1889. https://doi.org/10.1021/acs.orglett.9b00499. (d) Xie, S.; Li, S.; Ma, W.; Xu, X.; Jin, Z. Chelation-Directed Remote Meta-C-H Functionalization of Aromatic Aldehydes and Ketones. Chem. Commun. 2019, 55, 12408-12411. https://doi.org/10.1039/C9CC05807A.

(15) (a) Deng, Y.; Yu, J. Q. Remote Meta-C-H Olefination of Phenylacetic Acids Directed by a Versatile U-Shaped Template. Angew. Chem., Int. Ed. 2015, 54, 888-891. https://doi.org/10.1002/anie.201409860. (b) Dai, H. X.; Li, G.; Zhang, X. G.; Stepan, A. F.; Yu, J. Q. Pd(II)-Catalyzed Ortho - Or Meta-C-H Olefination of Phenol Derivatives. J. Am. Chem. Soc. 2013, 135, 7567-7571. https://doi.org/10.1021/ja400659s. (c) Wan, L.; Dastbaravardeh, N.; Li, G.; Yu, J. Q. Cross-Coupling of Remote Meta -C-H Bonds Directed by a U-Shaped Template. J. Am. Chem. Soc. 2013, 135, 18056-18059. https://doi.org/10.1021/ja410760f. (d) Yang, G.; Lindovska, P.; Zhu, D.; Kim, J.; Wang, P.; Tang, R. Y.; Movassaghi, M.; Yu, J. Q. Pd(II)-Catalyzed Meta-C-H Olefination, Arylation, and Acetoxylation of Indolines Using a U-Shaped Template. J. Am. Chem. Soc. 2014, 136, 10807-10813. https://doi.org/10.1021/ja505737x. (e) Fang, L.; Saint-Denis, T. G.; Taylor, B. L. H.; Ahlquist, S.; Hong, K.; Liu, S.; Han, L.; Houk, K. N.; Yu, J. Q. Experimental and Computational Development of a Conformationally Flexible Template for the Meta-C-H Functionalization of Benzoic Acids. J. Am. Chem. Soc. 2017, 139, 10702-10714. https://doi.org/10.1021/jacs.7b03296. (f) Xu, H. J.; Lu, Y.; Farmer, M. E.; Wang, H. W.; Zhao, D.; Kang, Y. S.; Sun, W. Y.; Yu, J. Q. $\mathrm{Rh}$ (III)-Catalyzed Meta-C-H Olefination Directed by a Nitrile Template. J. Am. Chem. Soc. 2017, 139, 2200-2203. https://doi.org/10.1021/jacs.6b13269. (g) Xu, H.-J.; Kang, Y.-S.; Shi, H.; Zhang, P.; Chen, Y.-K.; Zhang, B.; Liu, Z.-Q.; Zhao, J.; Sun, W.Y.; Yu, J.-Q.; et al. Rh(III)-Catalyzed Meta -C-H Alkenylation with Alkynes. J. Am. Chem. Soc. 2019, 141, 76-79. https://doi.org/10.1021/jacs.8b11038

(16) (a) Xu, H.; Liu, M.; Li, L.-J.; Cao, Y.-F.; Yu, J.-Q.; Dai, H.-X. Palladium-Catalyzed Remote Meta -C-H Bond Deuteration of Arenes Using a Pyridine Template. Org. Lett. 2019, 21, 4887-4891. https://doi.org/10.1021/acs.orglett.9b01784. (b) Xu, J.; Chen, J.; Gao, F.; Xie, S.; Xu, X.; Jin, Z.; Yu, J.-Q. Sequential Functionalization of Meta -C-H and Ipso -C-O Bonds of Phenols. J. Am. Chem. Soc. 2019, 141, 1903-1907. https://doi.org/10.1021/jacs.8b13403. (c) Chu, L.; Shang, M.; Tanaka, K.; Chen, Q.; Pissarnitski, N.; Streckfuss, E.; $\mathrm{Yu}$, J. Q. Remote Meta-C-H Activation Using a Pyridine-Based Template: Achieving Site-Selectivity via the Recognition of Distance and Geometry. ACS Cent. Sci. 2015, 1, 394-399. https://doi.org/10.1021/acscentsci.5b00312

(17) (a) Ramesh, P.; Satyanarayana, G. Palladium-Catalyzed Aerobic Oxidative Coupling of Ortho -(Alkynyl)Styrenes with Allylic Alcohols via 6- Endo-Dig Cyclization: Regioselective Construction of Polysubstituted Naphthalenes. J. Org. Chem. 2019, 84, 12856-12870. https://doi.org/10.1021/acs.joc.9b01240. (b) Kumar, D. R.; Gopi Krishna Reddy, A.; Satyanarayana, G. Palladium-Catalyzed Hydroxy Group Directed Regioselective Mono-Arylation of 2 Hydroxybiphenyls to 2-Hydroxy to Ortho-Terphenyls. Eur. J. Org. Chem. 2019, 2019, 2472-2480. https://doi.org/10.1002/ejoc.201801637. (c) Ravi Kumar, D.; Satyanarayana, G. Domino Oxidative [Pd]-Catalysis: One-Pot Synthesis of Fluorenones Starting from Simple Benzylamines and Iodo Arenes. 


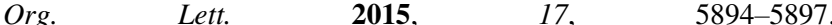
https://doi.org/10.1021/acs.orglett.5b03077.

(18) Frisch, M. J.; Trucks, G. W.; Schlegel, H. B.; Scuseria, G. E.; Robb, M. A.; Cheeseman, J. R.; Scalmani, G.; Barone, V.; Mennucci, B.; Petersson, G. A.; Nakatsuji, H.; Caricato, M.; Li, X.; Hratchian, H. P.; Izmaylov, A. F.; Bloino, J.; Zheng, G.; Sonnenberg, J. L.; Hada, M.; Ehara, M.; Toyota, K.; Fukuda, R.; Hasegawa, J.; Ishida, M.; Nakajima, T.; Honda, Y.; Kitao, O.; Nakai, H.; Vreven, T.; Montgomery, Jr. J. A.; Peralta, J. E.; Ogliaro, F.; Bearpark, M.; Heyd, J. J.; Brothers, E.; Kudin, K. N.; Staroverov, V. N.; Keith, T.; Kobayashi, R.; Normand, J.; Raghavachari, K.; Rendell, A.; Burant, J. C.; Iyengar, S. S.; Tomasi, J.; Cossi, M.; Rega, N.; Millam, J. M.; Klene, M.; Knox, J. E.; Cross, J. B.; et al. Gaussian 09, Revision C.01.

(19) Becke, A. D. Density-functional Thermochemistry. III. The Role of Exact Exchange. J. Chem. Phys. 1993, 98, 5648-5652.

(20) Hay, P. J.; Wadt, W. R. Ab Initio Effective Core Potentials for Molecular Calculations. Potentials for the Transition Metal Atoms Sc to Hg. J. Chem. Phys. 1985, 82, 270-283.

(21) Rassolov, V. A.; Pople, J. A.; Ratner, M. A.; Windus, T. L. $6-$ 31G* Basis Set for Atoms K through Zn. J. Chem. Phys. 1998, 109, $1223-1229$.

(22) Peng, C.; Schlegel, H. B. Combining Synchronous Transit and Quasi-Newton Methods to Find Transition States. Isr. J. Chem. 33, 449-454.

(23) Zhao, Y.; Truhlar, D. G. The M06 Suite of Density Functionals for Main Group Thermochemistry, Thermochemical Kinetics, Noncovalent Interactions, Excited States, and Transition Elements:
Two New Functionals and Systematic Testing of Four M06-Class Functionals and 12 Other Functionals. Theor. Chem. Acc. 2008, 120, 215-241.

(24) Andrae, D.; Häußermann, U.; Dolg, M.; Stoll, H.; Preuß, H. Energy-Adjustedab Initio Pseudopotentials for the Second and Third Row Transition Elements. Theor. Chim. Acta 1990, 77, 123-141.

(25) Marenich, A. V.; Cramer, C. J.; Truhlar, D. G. Universal Solvation Model Based on Solute Electron Density and on a Continuum Model of the Solvent Defined by the Bulk Dielectric Constant and Atomic Surface Tensions. J. Phys. Chem. B 2009, 113, 6378-6396.

(26) Glendening, E. D.; Reed, A. E.; Carpenter, J. E.; Weinhold, F. NBO Version 3.1, TCI. Univ. Wis. Madison 1998.

(27) Bondi, A. Van Der Waals Volumes and Radii. J. Phys. Chem. 1964, 68, 441-451. 


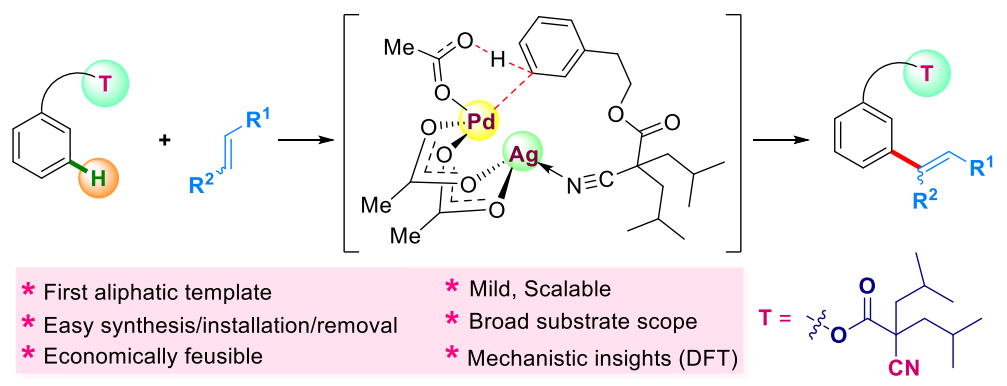

